Article

\title{
New Look on 3-Hydroxyiminoflavanone and Its Palladium(II) Complex: Crystallographic and Spectroscopic Studies, Theoretical Calculations and Cytotoxic Activity
}

\author{
Maria Kasprzak ${ }^{1, *}$, Małgorzata Fabijańska ${ }^{1}$, Lilianna Chęcińska ${ }^{2}$, Leszek Szmigiero ${ }^{3}$ and \\ Justyn Ochocki ${ }^{1}$ \\ 1 Department of Bioinorganic Chemistry, Medical University of Lodz, ul. Muszynskiego 1, Lodz 90-151 , \\ Poland; malgorzata.fabijanska@umed.lodz.pl (M.F.); justyn.ochocki@umed.lodz.pl (J.O.) \\ 2 Department of Theoretical and Structural Chemistry, Faculty of Chemistry, University of Lodz, \\ Pomorska 163/165, Lodz 90-236, Poland; lilach@uni.lodz.pl \\ 3 Department of Nucleic Acids Biochemistry, Medical University of Lodz, ul. Pomorska 251, Lodz 92-213, \\ Poland; leszek.szmigiero@umed.lodz.pl \\ * Correspondence: maria.kasprzak@umed.lodz.pl; Tel.: +48-426779220
}

Academic Editor: Derek J. McPhee

Received: 24 February 2016; Accepted: 28 March 2016; Published: 13 April 2016

\begin{abstract}
This work presents the synthesis, spectroscopic properties and single-crystal X-ray examination of the structure of 3-hydroxyiminoflavanone and its palladium complex. It presents the results of NMR (Nuclear Magnetic Resonance) spectroscopy, electron-density studies based on X-ray wavefunction refinement and theoretical calculations combined with QTAIM (Quantum Theory of Atoms in Molecules) and ELI-D (Electron Localizability Indicator) analyses. These offer an interesting new insight into the structures and behavior of flavanone and its complex, in solid state and in solution. The study also examines the cytotoxicity of the ligand and its complex against three human ovarian and lung cancer cell lines.
\end{abstract}

Keywords: palladium(II) complex; 3-hydroxyiminoflavanone; NMR spectroscopy; X-ray crystallography; $X$-ray wavefunction refinement; cytotoxicity

\section{Introduction}

Over the past 40 years, platinum-based drugs have been widely used in the treatment of many types of tumors including ovarian, testicular, non-small cell lung, head and neck and bladder cancers. Cisplatin (cis-[ $\left[\mathrm{PtCl}_{2}\left(\mathrm{NH}_{3}\right)_{2}\right]$, cis-diamminedichloridoplatinum) was found to be a particularly effective anticancer drug when administrated as single agent or in combination with other compounds. However, its application is limited by serious side effects such as nephrotoxicity, myelotoxicity, ototoxicity, allergy, and the development of resistance in tumor cells [1-3]. Palladium complexes have been studied extensively, based on their structural analogy with platinum complexes. A variety of $\mathrm{Pd}(\mathrm{II})$ complexes have shown promising activity as antitumor, antiviral, antimalarial, antifungal and antimicrobial agents [4-6]. However, most studies were not very encouraging because the $\mathrm{Pd}(\mathrm{II})$ complexes generally showed lower antitumor activity than cisplatin. This could be explained by the more labile nature of palladium complexes compared to their platinum homologues [7]. Nevertheless, some of the palladium complexes revealed higher antitumor activity than cisplatin or carboplatin. The Pd(II) complex of the coumarin-derived ligand demonstrated cytotoxic activity which was almost four orders of magnitude higher than that of carboplatin [8]. Preclinical studies have found flavonoids to have a broad spectrum of desirable effects including anticancer, antioxidant, antiviral, 
antibacterial and antiallergenic properties. Furthermore, beneficial synergistic interactions have been found between flavonoids and metal ions $[9,10]$. In addition, complexes with nitrogen-containing ligands are the subject of intensive biological evaluation in the search for less toxic and more selective anticancer agents [11].

Although our present study on 3-hydroxyiminoflavanone (1) and its $\mathrm{Pd}(\mathrm{II})$ complex (2) is a continuation of our preliminary studies on these compounds [12,13], it introduces novel, interesting findings which contrast with those obtained previously. For instance, while 3-hydroxyiminoflavanone was previously claimed to have 3Z(syn) geometry in solid state and in solutions [13], our present observations indicate it to have $3 E$ (anti) geometry in solid and in polar solvents. It was also found that 3-HIF only has 3Z(syn) geometry when dissolved in chloroform, and this exists in equilibrium with the $3 E$ (anti) isomer. Additionally, whereas an earlier study proposes that the coordination mode of the palladium complex of 3-HIF was via 4-carbonyl and 3-oxime oxygen atoms [12], our present findings indicate that the ligand chelates the $\mathrm{Pd}(\mathrm{II})$ ion via a 4-carbonyl group and a 3-nitrogen atom, while the oxime proton is lost and the ligand eventually becomes 3-nitrosoflavanone in the complex. This new evidence is confirmed by NMR (Nuclear Magnetic Resonance) spectroscopy, single crystal $\mathrm{X}$-ray studies and electron-density studies. This study is the first to compare cytotoxic properties of 3-hydroxyiminoflavonone and its $\mathrm{Pd}(\mathrm{II})$ complex with cisplatin towards three cancer cell lines.

\section{Results and Discussion}

\subsection{Synthesis of the Compounds $\mathbf{1}$ and $\mathbf{2}$}

The synthesis of 1 was described elsewhere [13] and reproduced here. In a molecule of flavanone, the carbon atom C3 (adjacent to carbonyl group) is nitrosated with isoamyl nitrate(III) in acidic environment, and the 3-oxime is formed (See Scheme 1). The resulting compound was obtained with good yield and purity (see the Materials and Methods Section), and purified by recrystallization.

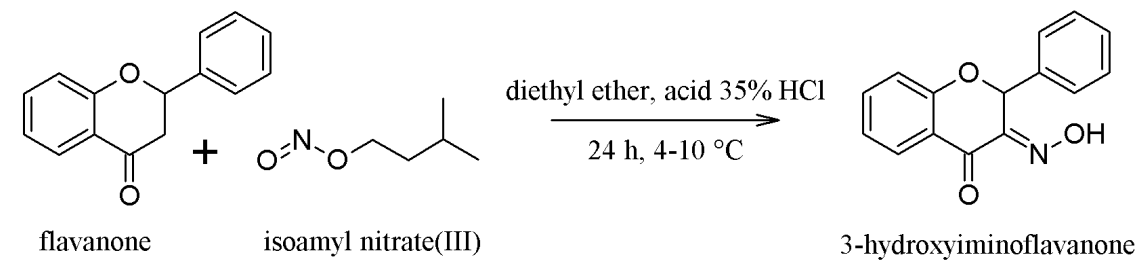

Scheme 1. Synthesis of 3-hydroxyiminoflavanone (1).

The synthesis of the palladium complex of 3-hydroxyiminoflavanone (2) was also performed earlier (see Scheme 2) [12]. However, whereas previous studies found the chelation to occur via the carbonyl oxygen and oxime oxygen atoms, which would lead to formation of six-membered rings, our results indicate that nitrogen atoms coordinate to the $\mathrm{Pd}(\mathrm{II})$ ion, and five-membered rings are formed in the complex. Moreover, the oxime hydrogen atoms are lost and the ligand occurs in the complex as 3-nitrosoflavanone.

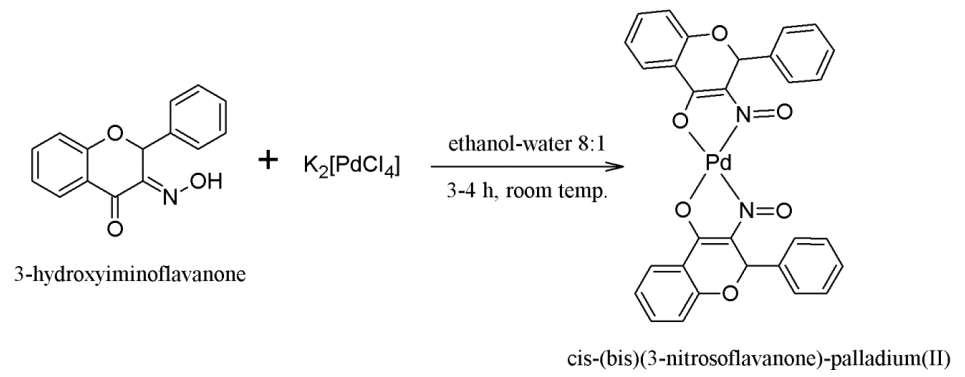

Scheme 2. Synthesis of cis-(bis)(3-nitrosoflavanone)-palladium(II)—compound 2. 


\subsection{Crystallography and Theoretical Calculations}

Figure 1a presents the molecular structure of compound $\mathbf{1}$ with an atom-numbering scheme, and Table 1 summarizes its crystal data. Molecule 1 consists of a benzene ring $(A)$ condensed with a six-membered heterocyclic ring $(C)$ that carries a phenyl ring $(B)$ and $=\mathrm{NOH}$ group. The carbon atom C9 is asymmetric. The system of two condensed rings $(A C)$ is rather planar: the maximum deviation of $0.138(1) \AA$ is observed for C9 atom from its least-square plane; the total puckering amplitude calculated for the 10-membered ring is 0.176(2) $\AA$; and the dihedral angle between the best planes of component rings $\left(A\right.$ and $C$ ) is $4.05(4)^{\circ}$. The phenyl ring $(B)$ is oriented almost perpendicular to the system of condensed rings and the corresponding dihedral angle is $87.99(6)^{\circ}$.

Table 1. Crystallographic data of $\mathbf{1}$ and 2.

\begin{tabular}{|c|c|c|}
\hline & 1 & 2 \\
\hline Empirical formula & $\mathrm{C}_{15} \mathrm{H}_{11} \mathrm{NO}_{3}$ & $\mathrm{C}_{30} \mathrm{H}_{20} \mathrm{~N}_{2} \mathrm{O}_{6} \mathrm{Pd} \cdot \mathrm{CHCl}_{3}$ \\
\hline Formula weight & 253.25 & 730.25 \\
\hline Crystal system, space group & Monoclinic, $P 2_{1} / \mathrm{n}$ & Triclinic, $P \overline{1}$ \\
\hline$a, b, c(\AA)$ & $8.6182(17), 5.7715(12), 23.468(5)$ & $10.3894(7), 10.9265(8), 13.1736(8)$ \\
\hline$\alpha, \beta, \gamma\left({ }^{\circ}\right)$ & $90.00,94.06(3), 90.00$ & $83.848(6), 80.996(5), 86.933(6)$ \\
\hline$V\left(\AA^{3}\right)$ & $1164.4(4)$ & $1467.50(17)$ \\
\hline Z & 4 & 2 \\
\hline$D_{\mathrm{x}}\left(\mathrm{Mg} / \mathrm{m}^{3}\right)$ & 1.445 & 1.653 \\
\hline Crystal size $(\mathrm{mm})$ & $0.25 \times 0.06 \times 0.03$ & $0.24 \times 0.13 \times 0.07$ \\
\hline Crystal habit and color & Plate, colorless & Plate, red \\
\hline$\lambda(\AA)$ & $0.71073\left(\mathrm{MoK}_{\alpha}\right)$ & $0.71073\left(\mathrm{MoK}_{\alpha}\right)$ \\
\hline$\mu\left(\mathrm{mm}^{-1}\right)$ & 0.10 & 0.95 \\
\hline$T(\mathrm{~K})$ & $100(2)$ & $100(2)$ \\
\hline Measured/unique reflections & $18731 / 3055$ & $12395 / 6905$ \\
\hline$R_{\text {int }}$ & 0.021 & 0.023 \\
\hline$\theta$ range $\left(^{\circ}\right)$ & $2.5-29.0$ & $3.1-28.0$ \\
\hline \multirow[t]{2}{*}{ Completeness to $\theta_{\max }(\%)$} & 98.9 & 97.2 \\
\hline & IAM model (spherical) & \\
\hline Observed reflections $[I>2 \sigma(I)]$ & 2741 & 5695 \\
\hline Data/restraints/parameters & $3055 / 0 / 176$ & $6905 / 0 / 429$ \\
\hline Refinement method & Full-matrix least-squares on $F^{2}$ & Full-matrix least-squares on $F^{2}$ \\
\hline$S$ & 1.112 & 0.927 \\
\hline$R[I>2 \sigma(I)], w R[I>2 \sigma(I)]$ & $0.0452,0.1009$ & $0.0257,0.0517$ \\
\hline$R$ (all data), wR (all data) & $0.0497,0.1034$ & $0.0351,0.0527$ \\
\hline$(\Delta / \sigma)_{\max }$ & $<0.001$ & 0.001 \\
\hline$\Delta \rho_{\max }\left(e \AA^{-3}\right), \Delta \rho_{\min }\left(e \AA^{-3}\right)$ & $0.40,-0.19$ & $0.50,-0.75$ \\
\hline & XWR: HAR model (aspherical) & \\
\hline Refinement method & on $F$ with weight $=1 / \sigma(|F|)$ & \\
\hline Functional/basis-set & blyp/cc-pVTZ & \\
\hline Data/restraints/parameters & $2974 / 0 / 216$ & \\
\hline$x^{2}$ & 10.17 & \\
\hline S & 3.19 & \\
\hline$R(F), w R(F)$ & $0.0340,0.0233$ & \\
\hline & XWR: XCW (fitting procedure) & \\
\hline Refinement method & on $F$ with weight $=1 / \sigma(|F|)$ & \\
\hline Functional/basis-set & blyp/cc-pVTZ & \\
\hline Data/restraints/parameters & 2974/0/1 & \\
\hline$\chi^{2}(\lambda=0.10)$ & 6.42 & \\
\hline$S$ & 2.53 & \\
\hline$R(F), w R(F)$ & $0.0303,0.0192$ & \\
\hline
\end{tabular}




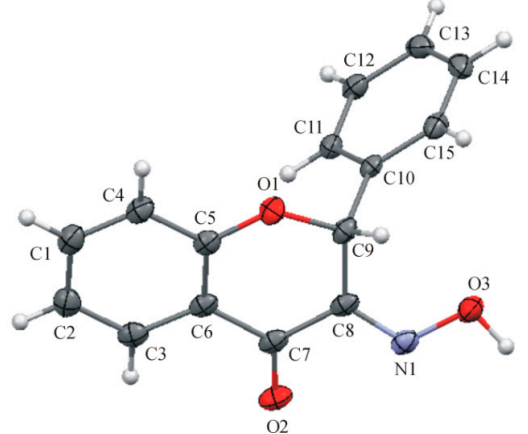

(a)

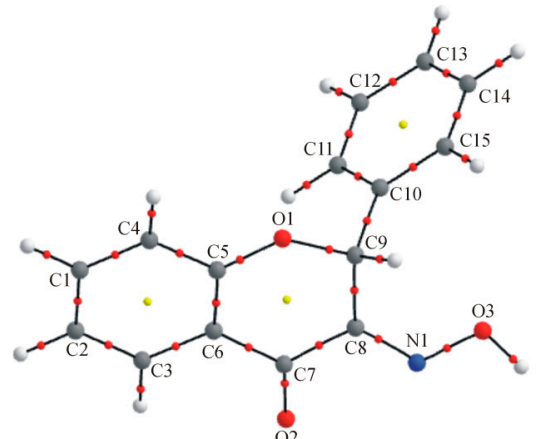

(c)

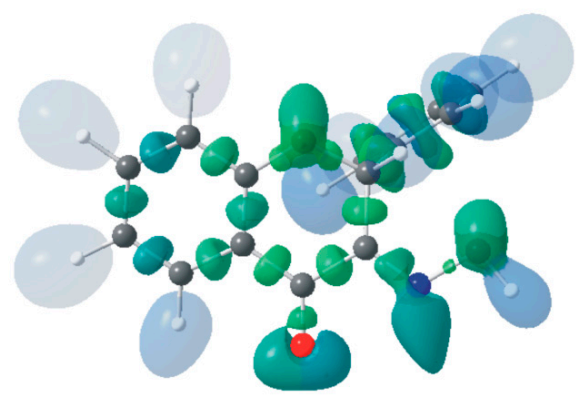

(e)

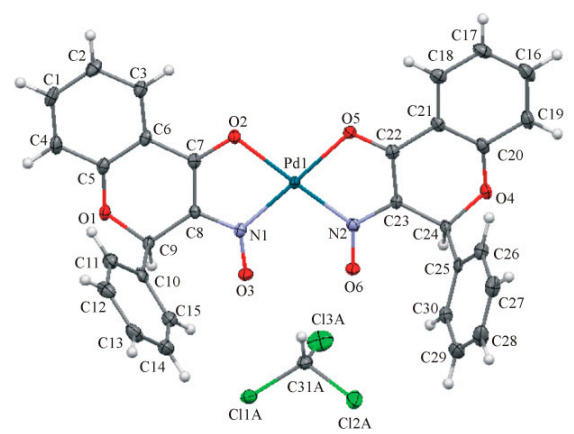

(b)

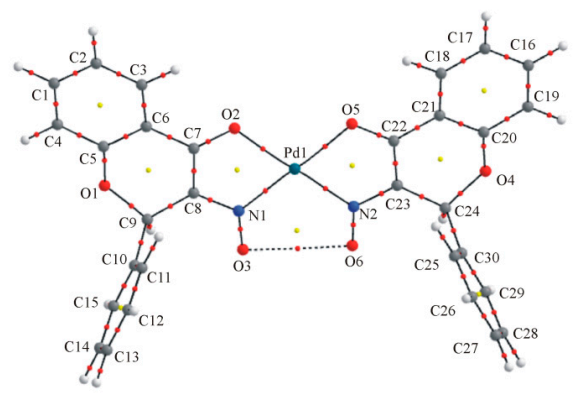

(d)

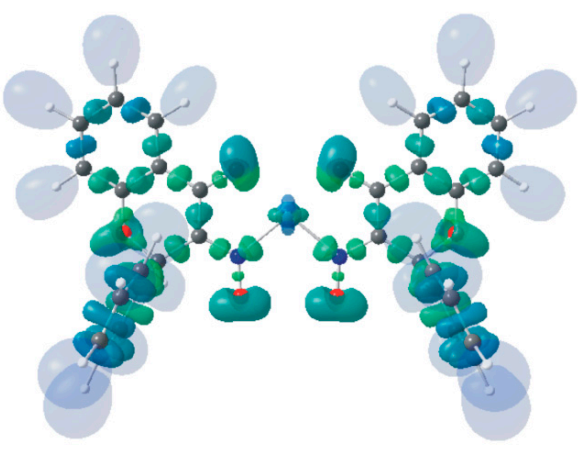

(f)

Figure 1. Molecular structures of 1 (a) and 2 (b) (both IAM models) showing 50\% probability ellipsoids and the crystallographic numbering schemes (MERCURY [14] representation). Only the major component $(A)$ of the disordered solvent molecule is shown. AIM-molecular graphs of XWR (X-ray wavefunction refinement)-model (1) (c) and OPT-model (2) (d); bond critical points are given as small red dots, and ring critical points are shown as small yellow dots. Isosurface representation of the localization domains of the ELI-D (an isovalue of $Y=1.40$ ) of XWR-model (1) (e) and OPT-model (2) (f). Transparent mode of the protonated monosynaptic valence basins (hydrogen basins) is applied for clarity reasons.

As well as a typical spherical Independent Atom Model (IAM), Hirshfeld Atom Refinement (HAR) [15,16] was used to acquire an aspherical structure model for molecule 1. Both structural models are in good agreement, the noticeable differences in bond lengths (of $0.013 \AA$ ) and valence angles (of $0.6^{\circ}$ ) only being observed for O3-N1 and O3-N1-C8, respectively. It is important to note that the Hirshfeld-atom model is more accurate than the spherical one, as all geometrical parameters are systematically obtained with smaller standard deviations. The selected bond lengths and valence angles determined for both experimental models of $\mathbf{1}$ are compared in Table S1 (Supplementary Materials). Figure 2a presents a scheme of intermolecular interactions characteristic of compound $\mathbf{1}$, and the geometries of interactions are given in Table 2. Two intermolecular hydrogen bonds, 
O3-H3A $\cdots \mathrm{O}^{\mathrm{i}}$ and O3-H3A $\cdots \mathrm{N}^{1}{ }^{\mathrm{i}}$ (symmetry code (i): $1-x, 1-y,-z$ ) are responsible for the formation of a cyclic dimer about a center of symmetry. As a result, a contact N1 $\cdots \mathrm{N} 1$ of 2.727(2) $\AA$ is also observed between the interacting molecules, which is shorter than the sum of the corresponding van der Waals radii (3.10 $\AA$ ). Furthermore, the supramolecular structure of $\mathbf{1}$ is dominated by weak $\mathrm{C}-\mathrm{H} \cdots \mathrm{O}$ interactions: $\mathrm{C} 9-\mathrm{H} 9 \cdots \mathrm{O} 2(x, y-1, z)$ and $\mathrm{C} 3-\mathrm{H} 3 \cdots \mathrm{O} 2(-x, 2-y,-z)$, which link the adjacent dimers into two-dimensional molecular layers in the $a b$ plane. The layer-structure is additionally stabilized by weak $\mathrm{C} 1-\mathrm{H} 1 \cdots \pi(\operatorname{ring} C ; x-1, y, z)$ interactions and close $\mathrm{C} \cdots \mathrm{O}$ contacts: $\mathrm{C} 1 \cdots \mathrm{O} 3(x$ $-1, y, z)(3.204(2) \AA)$ and O1‥C3 $(x, y-1, z)(3.206(2) \AA)$. No specific interactions between adjacent layers were found. The X-ray diffraction study of compound 2 shows that the asymmetric unit contains a palladium cation and two flavanone ligands in anionic form arranged in a cis-configuration; additionally, a trichloromethane solvent molecule is also observed. The perspective view of molecular structure of $\mathbf{2}$ is shown in Figure $1 \mathrm{~b}$. The $\mathrm{Pd}$ (II) center is four coordinated in bis-bidendate fashion via two $\mathrm{N}$ (oxime) and two $\mathrm{O}$ (carbonyl) atoms, thus the coordination geometry is distorted square planar with angles varying from $81.25(6)^{\circ}$ to $99.92(6)^{\circ}$ (Table S1 in Supplementary Materials).

The Pd-N [1.9898(16) $\AA$ and 1.9809(16) $\mathrm{A}]$ and Pd-O [2.0586(13) $\AA$ and 2.0636(13) $\AA$ ] bond lengths are comparable with those reported for related $\mathrm{Pd}(\mathrm{II})$ complexes $[17,18]$. The coordination of the $\mathrm{Pd}(\mathrm{II})$ ion results in the formation of two five membered chelate rings, $\mathrm{Pd} 1 / \mathrm{O} 2 / \mathrm{C} 7 / \mathrm{C} 8 / \mathrm{N} 1$ and $\mathrm{Pd} 1 / \mathrm{O} 5 / \mathrm{C} 22 / \mathrm{C} 23 / \mathrm{N} 2$, which are essentially planar and form a dihedral angle of $3.21(7)^{\circ}$.

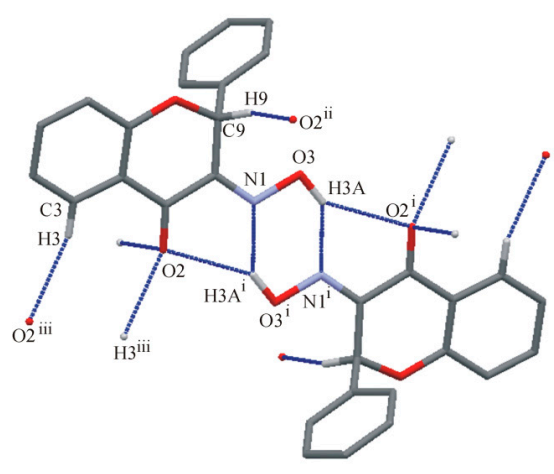

(a)

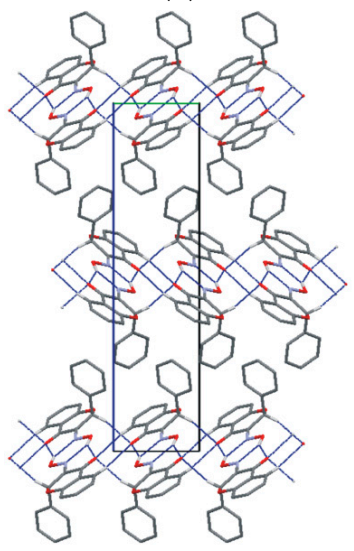

(c)

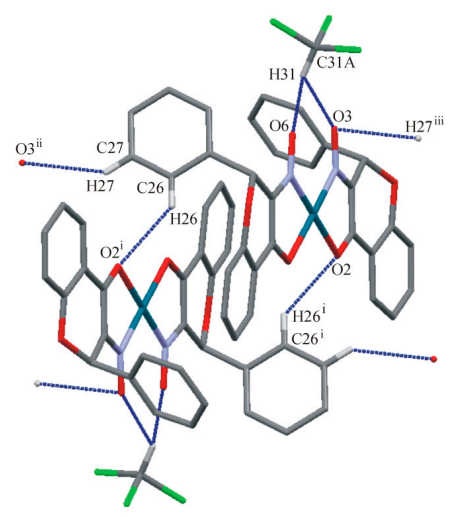

(b)

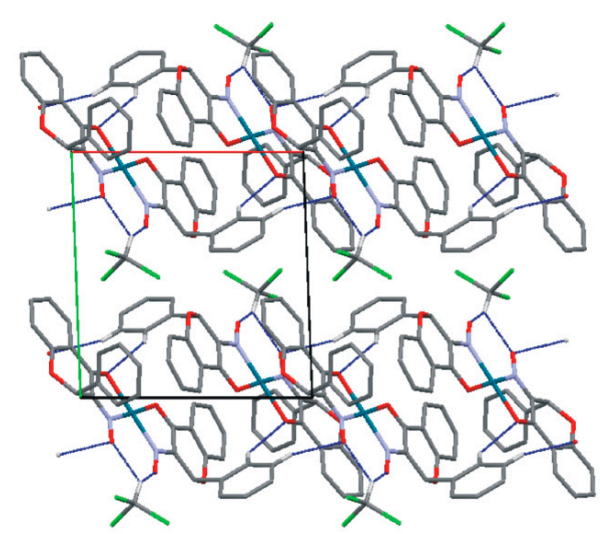

(d)

Figure 2. The schemes of intermolecular interactions of free-ligand (1) (a) and its Pd(II)-complex (2) (b). Crystal packing of $\mathbf{1}$ along $a$ axis showing the organization of molecular layers $a b$ (c) and chains of supramolecular dimers in structure 2 viewing along $c$ axis (d). Symmetry codes: for 1 : (i) $1-x, 1-y$, $-z$; (ii) $x, y-1, z$; and (iii) $-x, 2-y,-z$. Symmetry codes for 2 : (i) $1-x,-y, 1-z$; (ii) $x+1, y, z$; and (iii) $x-1, y, z$. 
Table 2. The geometries of intermolecular interactions of $\mathbf{1}$ and $\mathbf{2}$ a.

\begin{tabular}{|c|c|c|c|c|}
\hline Interaction & D-H & $\mathbf{H} \cdots \mathbf{A}$ & $\mathbf{D} \cdots \mathbf{A}$ & D-H $\cdots A$ \\
\hline \multicolumn{5}{|c|}{1} \\
\hline $\mathrm{O} 3-\mathrm{H} 3 \mathrm{~A} \cdots \mathrm{O} 2^{\mathrm{i}}$ & $0.96(2)$ & $2.49(2)$ & $3.3359(18)$ & $146(2)$ \\
\hline $\mathrm{O} 3-\mathrm{H} 3 \mathrm{~A} \cdots \mathrm{N} 1^{\mathrm{i}}$ & $0.96(2)$ & $1.98(2)$ & $2.7996(18)$ & $142(2)$ \\
\hline $\mathrm{C} 9-\mathrm{H} 9 \ldots \mathrm{O} 2{ }^{\mathrm{ii}}$ & 0.98 & 2.41 & $3.283(2)$ & 147 \\
\hline $\mathrm{C} 3-\mathrm{H} 3 \cdots \mathrm{O} 2{ }^{\mathrm{iii}}$ & 0.93 & 2.46 & $3.297(2)$ & 149 \\
\hline $\mathrm{C} 1-\mathrm{H} 1 \cdots \mathrm{Cg}^{\mathrm{ii}, \mathrm{b}}$ & 0.93 & 2.79 & $3.628(2)$ & 150 \\
\hline \multicolumn{5}{|c|}{2} \\
\hline 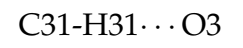 & $0.99(2)$ & $2.26(2)$ & $2.990(4)$ & 130(2) \\
\hline 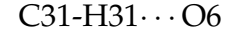 & $0.99(2)$ & $1.29(3)$ & $2.964(4)$ & 124(2) \\
\hline $\mathrm{C} 26-\mathrm{H} 26 \cdots \mathrm{O} 2^{\mathrm{i}}$ & 0.93 & 2.51 & $3.259(2)$ & 137 \\
\hline $\mathrm{C} 27-\mathrm{H} 27 \cdots \mathrm{O} 33^{\mathrm{ii}}$ & 0.93 & 2.63 & $3.395(2)$ & 140 \\
\hline
\end{tabular}

a distances $\mathrm{D}-\mathrm{H}, \mathrm{H} \cdots \mathrm{A}$ and $\mathrm{D} \cdots \mathrm{A}$ in $\AA$, angle D-H $\cdots \mathrm{A}$ in deg; ${ }^{\mathrm{b}} \mathrm{Cg}-$ is the centroid of the phenyl ring $\mathrm{C}$ (C10-C15); Symmetry codes: for $\mathbf{1}^{\mathrm{i}} 1-x, 1-y,-z$; ${ }^{\text {ii }} x, y-1, z$; iii $-x, 2-y,-z$; for ${ }^{\mathrm{i}}{ }^{\mathrm{i}} 1-x,-y, 1-z$; ii $x+1, y, z$.

The Cremer and Pople's ring puckering parameters [19] calculated for the six-membered heterocyclic rings: O1/C5-C9 [ $\left.Q_{T O T}=0.2651(19) \AA, \theta=119.6(4)^{\circ}, \phi=140.8(5)^{\circ}\right]$ and O4/C20-C24 $\left[Q_{T O T}=0.2190(18) \AA, \theta=65.7(5)^{\circ}, \phi=326.1(6)^{\circ}\right]$ show that both adopt skew-boat conformation in contrast to free ligand 1, where the corresponding ring was essentially planar. Accordingly, the asymmetry parameters [20] $\left[\Delta \mathrm{C}_{2}(\mathrm{O} 1-\mathrm{C} 9)=3.9(3)^{\circ}\right.$ and $\left.\Delta \mathrm{C}_{2}(\mathrm{O} 4-\mathrm{C} 24)=1.2(3)^{\circ}\right]$ imply the existence of the pseudo-twofold-axis crossing the mid-points of the opposite bonds of the analyzed rings. The planar fragments of the phenyl ring and benzene ring molecules (condensed with a puckered six-membered ring) form angles of $79.19(9)^{\circ}$ and $77.8(1)^{\circ}$, respectively. In describing complex structure 2 , it is important to note that upon coordination, flavanone ligand 1 undergoes significant evolution from its oxime to nitroso form (additionally anionic), demonstrated by its experimentally and theoretically obtained geometrical, topological and integrated parameters.

The topological analysis of the investigated flavanone ligand $\mathbf{1}$ and Pd-complex $\mathbf{2}$ structures was performed based on the Quantum Theory of Atoms in Molecules (QTAIM) [21]. While two models of electron-density distribution were considered for compound 1, i.e., an experimental model obtained from X-ray wavefunction refinement (1-XWR) [22] and a theoretical one derived by DFT-geometry optimization (1-OPT), only a theoretical electron-density model was available for compound 2. The molecular graphs of XWR-model of $\mathbf{1}$ and OPT-model of $\mathbf{2}$ are presented in Figure 1c,d and compared with corresponding ELI-D-representations (Figure 1e-f). The combination of the QTAIM and ELI-D $[23,24]$ approaches provides quantitative information concerning the nature of the bonding present in the analyzed structures. Table 3 presents the topological properties of the bonds derived from QTAIM space partitioning and a set of ELI-D derived properties from the models of $\mathbf{1}$ and $\mathbf{2}$.

Overall, since systematically slightly longer distances in DFT-models are expected and acceptable, the agreement between the experimentally-observed and theoretically-calculated structures is very good and structural trends are maintained.

The analysis of geometrical parameters reveals a considerable shortening of bond lengths $\mathrm{C} 7-\mathrm{C} 8 / \mathrm{C} 22-\mathrm{C} 23$ and O3-N1/O6-N2 (ligand 1/ligand 2) in complex structure 2 in comparison to $\mathrm{C} 7-\mathrm{C} 8$ and $\mathrm{O} 3-\mathrm{N} 1$ in the free ligand structure of 1 . Concomitantly, a significant lengthening of bond distances $\mathrm{O} 2-\mathrm{C} 7 / \mathrm{O} 5-\mathrm{C} 22$ and N1-C8/N2-C23 is observed. 
Table 3. Geometrical ${ }^{\mathrm{a}}$, topological ${ }^{\mathrm{b}}$ and integrated ${ }^{\mathrm{c}}$ bond descriptors determined for selected bonds in XWR-model of $\mathbf{1}$ and OPT-model of $\mathbf{2}^{\mathrm{d}}$.

\begin{tabular}{|c|c|c|c|c|c|c|c|c|c|c|c|c|}
\hline Bond & $d$ & $\rho_{\text {bcp }}$ & $\nabla^{2} \rho_{\mathrm{bcp}}$ & $\varepsilon$ & $G / \rho_{\mathrm{bcp}}$ & $H / \rho_{\text {bcp }}$ & $\delta$ & $V_{\text {ELI }}$ & ELI $_{\text {pop }}$ & $Y_{\max }$ & $\Delta_{\text {ELI }}$ & $R J I$ \\
\hline \multicolumn{13}{|c|}{ (1-XWR) } \\
\hline O1-C5 & $1.3520(6)$ & 1.94 & -7.6 & 0.04 & 1.15 & -1.43 & 0.96 & 1.16 & 1.39 & 1.56 & 0.06 & 78.4 \\
\hline O1-C9 & $1.4405(6)$ & 1.61 & -9.6 & 0.07 & 0.87 & -1.29 & 0.80 & 1.21 & 1.40 & 1.58 & 0.06 & 82.3 \\
\hline $\mathrm{O} 2-\mathrm{C} 7$ & $1.2218(5)$ & 2.75 & -10.9 & 0.16 & 1.42 & -1.70 & 1.37 & 4.28 & 2.29 & 1.54 & 0.04 & 73.2 \\
\hline O3-N1 & $1.3641(5)$ & 2.24 & -7.6 & 0.03 & 0.67 & -0.90 & 1.34 & 0.56 & 0.99 & 1.46 & 0.02 & 55.0 \\
\hline N1-C8 & $1.2856(6)$ & 2.57 & -22.8 & 0.39 & 0.92 & -1.54 & 1.50 & 6.88 & 3.08 & 1.71 & 0.17 & 69.2 \\
\hline C5-C6 & $1.4026(6)$ & 2.09 & -23.3 & 0.25 & 0.36 & -1.14 & 1.25 & 7.92 & 2.87 & 1.82 & 0.03 & 54.2 \\
\hline C6-C7 & $1.4614(7)$ & 1.96 & -21.7 & 0.12 & 0.27 & -1.05 & 1.04 & 4.84 & 2.38 & 1.95 & 0.01 & 50.8 \\
\hline C7-C8 & $1.4839(7)$ & 1.89 & -20.2 & 0.15 & 0.26 & -1.01 & 0.95 & 5.22 & 2.40 & 1.97 & 0.03 & 52.1 \\
\hline C8-C9 & $1.5015(7)$ & 1.79 & -17.9 & 0.15 & 0.26 & -0.96 & 0.94 & 3.82 & 2.21 & 1.95 & 0.05 & 55.9 \\
\hline \multicolumn{13}{|c|}{ (2-OPT) } \\
\hline N1-Pd1 & 2.032 & 0.80 & 8.2 & 0.07 & 1.07 & -0.36 & 0.76 & 6.42 & 2.53 & 1.77 & 0.09 & 94.5 \\
\hline O2-Pd1 & 2.112 & 0.57 & 8.6 & 0.04 & 1.27 & -0.22 & 0.56 & 2.80 & 2.02 & 1.61 & 0.03 & 97.1 \\
\hline O1-C5 & 1.364 & 1.97 & -14.1 & 0.05 & 0.95 & -1.45 & 0.97 & 1.23 & 1.47 & 1.59 & 0.05 & 76.1 \\
\hline O1-C9 & 1.485 & 1.51 & -11.3 & 0.03 & 0.61 & -1.14 & 0.83 & 1.10 & 1.24 & 1.56 & 0.06 & 76.4 \\
\hline $\mathrm{O} 2-\mathrm{C} 7$ & 1.286 & 2.40 & -15.5 & 0.07 & 1.14 & -1.60 & 1.19 & 1.94 & 1.82 & 1.57 & 0.01 & 73.7 \\
\hline N1-O3 & 1.249 & 3.15 & -21.7 & 0.06 & 0.74 & -1.22 & 1.66 & 0.90 & 1.50 & 1.50 & 0.02 & 56.8 \\
\hline N1-C8 & 1.359 & 2.18 & -19.6 & 0.34 & 0.77 & -1.40 & 1.22 & 3.86 & 2.51 & 1.72 & 0.05 & 75.1 \\
\hline C5-C6 & 1.420 & 2.05 & -22.2 & 0.20 & 0.32 & -1.08 & 1.23 & 7.68 & 2.79 & 1.87 & 0.04 & 53.5 \\
\hline C7-C6 & 1.458 & 1.92 & -19.8 & 0.14 & 0.27 & -0.99 & 1.07 & 5.57 & 2.46 & 1.95 & 0.03 & 53.2 \\
\hline C8-C7 & 1.423 & 2.07 & -22.6 & 0.22 & 0.31 & -1.07 & 1.14 & 10.21 & 3.16 & 1.90 & 0.01 & 56.7 \\
\hline C8-C9 & 1.508 & 1.74 & -16.0 & 0.09 & 0.24 & -0.88 & 0.95 & 3.51 & 2.16 & 1.98 & 0.02 & 52.4 \\
\hline $\begin{array}{l}{ }^{\mathrm{a}} d- \\
\mathrm{bon} \\
\text { valı } \\
\text { axis } \\
\text { pop } \\
\text { con } \\
\text { for }\end{array}$ & Lneligo & , & $\mathrm{n} ; \Delta_{\mathrm{ELI}}$ & 3 & 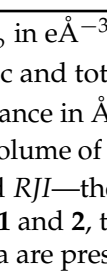 & ग & I & IIOn & endicu & to th & $\begin{array}{l}-5 ; \varepsilon- \\
x-E L \\
\text { tom-at }\end{array}$ & \\
\hline
\end{tabular}

Such geometrical changes are reflected in topological parameters determined in bond critical points (bcps); electron density values at bcp increased or decreased when the distance was shortened or lengthened, respectively. Furthermore, these trends are confirmed by the bond ellipticity value $(\varepsilon)$ [25] and delocalization index $(\delta)[26,27]$. Literature ellipticity equals 0 for a perfectly isolated single $C-C$ bond and $\varepsilon=0.23$ for a 1.5-fold bond in benzene; a delocalization index value of $\delta_{\mathrm{A}, \mathrm{B}}=1$ is assigned to a single Lewis pair equally shared between two atoms, A and B, while a value higher than 1 is awarded when the two atoms share more than one electron pair between their respective basins.

In our study, the following parameters amount $\varepsilon_{\mathrm{C} 7-\mathrm{C} 8}=0.15$ and $\delta_{\mathrm{C} 7, \mathrm{C} 8}=0.95$ in were found 1 (the XWR model) and both increase upon complexation to 0.22 and 1.14, respectively (2-OPT model). On the other hand, considerable greater $\delta$ values are encountered for the formal double bonds O2-C7 and N1-C 8 in $1\left(\delta_{\mathrm{O} 2, \mathrm{C} 7}=1.37, \delta_{\mathrm{N} 1, \mathrm{C} 8}=1.50\right)$ than in $\mathbf{2}\left(\delta_{\mathrm{O} 2, \mathrm{C} 7}=1.19, \delta_{\mathrm{N} 1, \mathrm{C} 8}=1.22\right)$. A reversed trend is observed for the N1-O3 bond, $\delta_{\mathrm{N} 1, \mathrm{O} 3}=1.34$ in 2 vs. $\delta_{\mathrm{N} 1, \mathrm{O} 3}=1.66$ in $\mathbf{1}$, which is additionally supported by increasing the value of the ratio $H / \rho_{\mathrm{bcp}}[28]$, indicating a degree of bond covalence.

To summarize, in $\mathrm{Pd}(\mathrm{II})$ complex structure 2, the structural fragments within the flavanone moieties O2-C7-C8-N1-O3 (ligand 1) and O5-C22-C23-N2-O6 (ligand 2) clearly contain delocalized $\pi$-systems. Figure 3 presents two possible resonance forms of 2 . In the solid state, form 1 (Figure 3 ) of complex structure 2 is determined. Table S2 summarizes the population of (non-bonding) lone pair basins obtained using the ELI-D technique. Two basins belonging to the lone pair region of the oxygen $\mathrm{O} 2$ (carbonyl) atom in structure 1 can be distinguished, each around $8 \AA^{3}$ populating $5.24 e$ in total, whereas this space is contracted in complex 2 , the population being reduced to $3.56 e$ (O5 atom in 
ligand 2). In contrast, the population of lone pairs of oxygen O3(oxime) atoms increases from $4.68 e$ integrated in free neutral ligand 1 to $5.62 \mathrm{e}$ in structure.

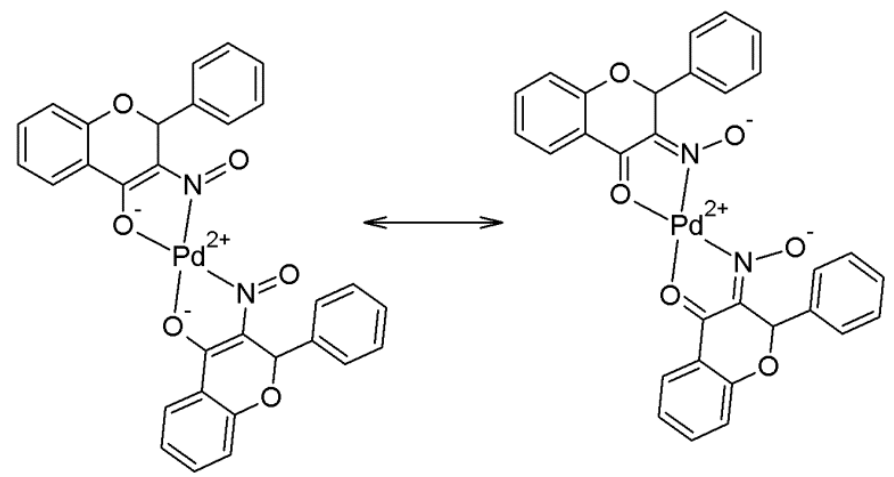

Figure 3. Two resonance forms of Pd(II) complex 2.

Moreover, an inspection of Figure 1e-f, Table 3 and Table S4 (Supplementary Materials) clearly indicates that the oxygen $\mathrm{O} 2$ and $\mathrm{O} 5$ atoms form a fairly strong ionic interaction to the metal center $\mathrm{Pd}(\mathrm{II})$, as confirmed by a Raub-Jansen index [29,30] of $97 \%$ and the highest value of degree of iconicity $\left(G / \rho_{\mathrm{bcp}}\right)$ observed in structure 2 .

Pd1-N1 and Pd1-N2 bonds have more of a polar character $(R J I=94.5 \%)$ with relatively greater electron density in bcp and smaller $G / \rho_{\mathrm{bcp}}$ ratio, but higher $H / \rho_{\mathrm{bcp}}$ and $\delta_{\mathrm{N} 1, \mathrm{Pd} 1}$ in comparison to O-Pd bonding.

The crystal packing of $\mathbf{2}$ is dominantly arranged by weak interactions. First of all, the complex molecule interacts with the solvent molecule via two C31A-H31 ․ O3 and C31A-H31 . O6 interactions (Table 2). Such molecular pairs form supramolecular centrosymmetric dimers with C26-H26 ․ O2 $(1-x,-y, 1-z)$ interaction (Figure $2 b)$, which subsequently organize into infinite chains along the crystallographic $a$ axis by $\mathrm{C} 27-\mathrm{H} 27 \cdots \mathrm{O} 3(x+1, y, z)$ contacts. The final packing arrangement of 2 is shown in Figure 2d. Finally, it is interesting to note that the QTAIM analysis of close intramolecular O3 . . O6 contact (2.878 $\AA$-IAM model, $2.977 \AA$-OPT model) shorter than the sum of van der Waals radii of interacting atoms (3.04 $\AA$ ) revealed the following topological parameters at its bcp: electron density $\rho_{\mathrm{bcp}}=0.06 e \AA^{-3}$ and associated Laplacian $\nabla^{2} \rho_{\mathrm{bcp}}=0.7 e \AA^{-5}$ (Figure 2d). This weak non-covalent interaction seems not to affect the ELI-D lone-pair basins of O3 and O6 oxygen atoms (Figure 1f), suggesting that it results from the spatial arrangement of coordinating flavanone ligands.

\subsection{NMR Spectroscopic Analysis and Solution Stability Studies}

\subsubsection{Compound $\mathbf{1}$}

The results of the ${ }^{1} \mathrm{H}-\mathrm{NMR}$ analysis of 1 in DMSO- $d_{6}$ are generally in agreement with those described by Kostka and Zyner [13]. The signals between 6.9-7.9 ppm are typical for the flavanone moiety. The oxime proton signal is visible at $13.39 \mathrm{ppm}$, and its integration value suggests that the molecule only has an oxime tautomeric form (Figure 4). However, our results differ regarding the significance of the observed downfield shift of the oxime proton signal: while Kostka and Zyner [13] suggest that the shift indicates 3Z(syn) geometry of the molecule, our results indicate that the ligand exists as an $E$ (anti) isomer rather than $Z$ (syn), both in solid form and in DMSO solution. The downfield-shifted signal of the oxime proton is not necessarily due to the presence of an intramolecular hydrogen bond in 3Z(syn)-HIF [13], but it is typical for the oxime proton in similar molecules [31-33]. Additionally, the signals of aromatic protons from the phenyl ring B of the flavanone moiety are split in two parts (7.24-7.28 ppm for the $2 \mathrm{H}$ bound to the ortho carbon atoms, and 7.30-7.38 ppm for the $3 \mathrm{H}$ bound to the meta and para carbon atoms, ring $\mathrm{C}$ ), which indicates the presence of steric interaction between the phenyl group and the oxime -OH group in the anti position. 
Therefore, the ${ }^{1} \mathrm{H}$-NMR spectrum of $\mathbf{1}$ in DMSO- $d_{6}$ displays the pattern for $3 E$-hydroxyiminoflavanone (Figure 4). However, when the ${ }^{1} \mathrm{H}-\mathrm{NMR}$ spectrum of $\mathbf{1}$ is made using $\mathrm{CDCl}_{3}$ as solvent, the pattern is different (Figure S2 in Supplementary Materials). The signal of the labile proton is very weak and very broad (often hardly visible), at 10.15 ppm (Figure S3 in Supplementary Materials). The signals of aromatic protons from the phenyl ring B of the flavanone moiety are not split, but are seen as a large multiplet, suggesting that the aromatic protons of ring $\mathrm{B}$ do not interact with the polar oxime group. Even so, after $24 \mathrm{~h}$, a small singlet exchangeable with $\mathrm{D}_{2} \mathrm{O}$ appears at $14.91 \mathrm{ppm}$ (Figure S2), which could possibly be the signal from the $-\mathrm{NOH}$ group, along with additional signals at 6.29, 7.12, 7.17, 7.65 and $7.95 \mathrm{ppm}$, which indicates the formation of an equilibrium between two isomeric forms of 1 .

After six days in solution, the emerging isomer constitutes almost $30 \%$ of the total amount, and its signal pattern is similar to that seen in DMSO- $d_{6}$, indicating the formation of $3 E-H I F$ (Figure S2 in Supplementary Materials). That suggests that the initial form $\mathbf{1}$ takes after dissolution in chloroform is 3Z-HIF. This has been confirmed by Enchev et al. [33] in the case of 4-nitroso-5-pyrazolones, and by Belmar et al. [32] in the case of 1-(2-hydroxyethyl)-3-methyl-4-hydroxyimino-5-pyrazolone, where a polar solvent (DMSO) supports the formation of the $E$ diastereoisomer, and a non-polar solvent, i.e., chloroform, supports the formation of the $\mathrm{Z}$ form. Enchev et al. [34] describe the tautomeric and conformational equilibrium of 9,10-phenantrenequinonemonooxime, where the most prevalent form of the molecule in chloroform is the $\mathrm{Z}$ isomer, and in DMSO the $E$ isomer. The nitroso tautomers are not thermodynamically preferred, and unlikely to exist in solution [33]. In the case of 3-HIF, the existence of the nitroso-enol tautomer is not supported by the data. ${ }^{13} \mathrm{C}-\mathrm{NMR}$ spectra recorded in DMSO- $d_{6}$ and $\mathrm{CDCl}_{3}$ reveal a signal assigned to the carbonyl carbon atom near $177 \mathrm{ppm}$ (Figure S5 in Supplementary Materials), which is typical for carbonyl carbon atoms $\mathrm{C}=\mathrm{O}[31,32]$. Signals from $\mathrm{C}-\mathrm{OH}$ carbon atoms should be right-shifted towards around $160 \mathrm{ppm}[32,35]$.

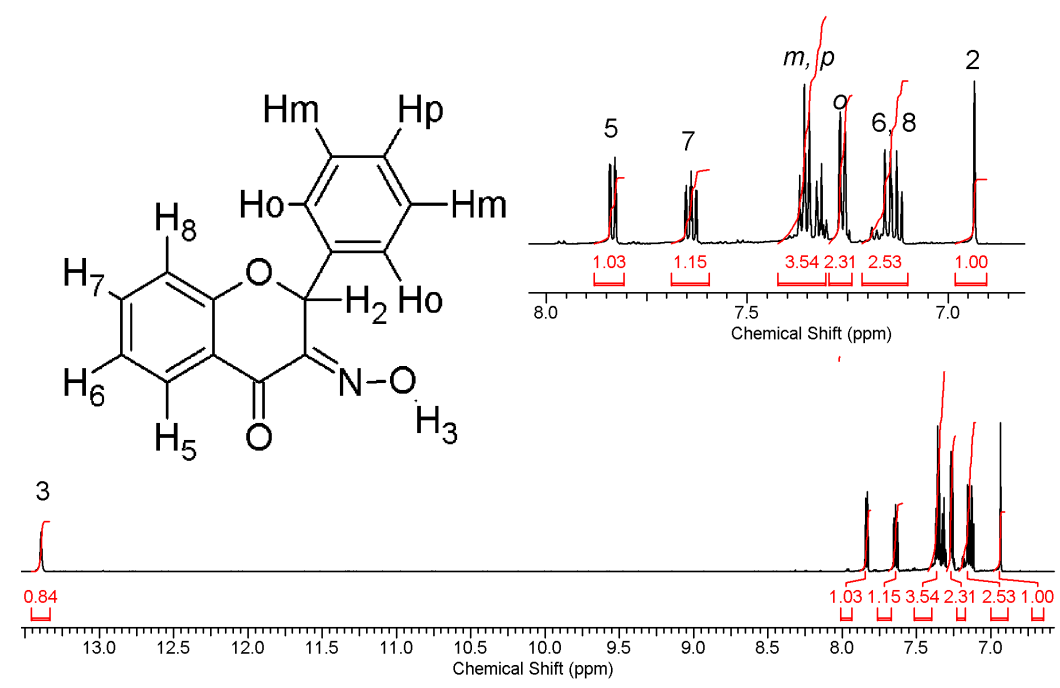

Figure 4. ${ }^{1} \mathrm{H}-\mathrm{NMR}$ (Nuclear Magnetic Resonace) spectrum of $\mathbf{1}$ in DMSO- $d_{6}$, with integration values and assignments.

\subsubsection{Compound 2}

Again, our results are in contrast with those of previous preliminary studies, which suggest that only oxygen atoms coordinate with Pd(II) [12]. This claim was made on the basis of IR spectra, which only indicated the presence of Pd-O bonds. However, such an interpretation can be misleading, due to overlapping signals of similar, but not identical types of bonds. Our crystallographic data show that coordination bonds are formed by nitrogen and oxygen atoms, and the oxime hydrogen atoms are lost during the coordination. This is also in agreement with ${ }^{1} \mathrm{H}-\mathrm{NMR}$ data, where no signal from labile proton is observed (Figure 5). 
As the complex was used in biological in vitro study, its stability was determined using UV-Vis spectroscopy, in an aqueous environment at $37^{\circ} \mathrm{C}$ to mimic the conditions in the cell culture incubator. The absorption spectrum has two maxima, at $316 \mathrm{~nm}$ and at $461 \mathrm{~nm}$. Compound 2 in solution seems to be stable, and the spectrum shows practically no changes for up to $62 \mathrm{~h}$ of incubation, with no shifts of the maxima. The spectra are shown in the Figure S4 in the Supplementary Materials.

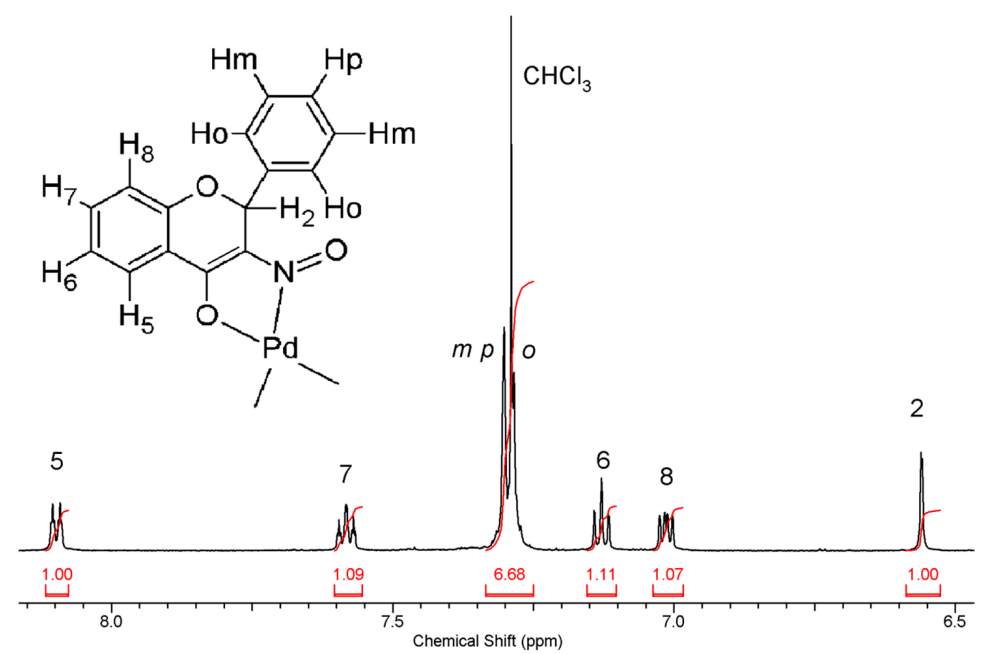

Figure 5. ${ }^{1} \mathrm{H}-\mathrm{NMR}$ spectrum of 2 in $\mathrm{CDCl}_{3}$, with integration values and assignments.

\subsection{Cytotoxicity Assay (3-(4,5-Dimethylthiazol-2-yl)-2,5-diphenyltetrazolium Bromide or MTT Assay)}

The three cell lines used, A2780, A2780cis and A549, have different degrees of sensitivity to cisplatin. The most sensitive line is A2780 (human ovarian carcinoma), with $\mathrm{IC}_{50}$ below $1 \mu \mathrm{M}$. A2780cis is a commercially-available subline resistant to cisplatin, with an $\mathrm{IC}_{50}$ about $20 \mu \mathrm{M}$. The A549 cells (human non-small cell lung carcinoma) have relatively high intrinsic resistance to cisplatin, with an $\mathrm{IC}_{50}$ of approximately $4 \mu \mathrm{M}$ (for details see Table 4 , and Figure $\mathrm{S} 6$ in Supplementary Materials). Compound $\mathbf{1}$ is less cytotoxic than $\mathbf{2}$ and CDDP, with only a small antiproliferative effect up to a concentration of $25 \mu \mathrm{M}$ (See Figure S6). IC 50 values are given in Table 4. However, the fact that 1 is significantly cytotoxic at the concentration below $100 \mu \mathrm{M}$ suggests that the choice of ligand substantially contributes to the toxicity of the complex 2. As compound 2, cis-(bis)(3-nitrosoflavanone) palladium(II), was insoluble in water and barely soluble in DMSO, the maximal concentration tested in the cell culture was $15 \mu \mathrm{M}$. The low solubility of 2 is possibly due to the lack of polar moieties on the surface of the molecule, and its electric neutrality. It was not possible to determine the $\mathrm{IC}_{50}$, because at this concentration the decrease in the cell proliferation was less than $50 \%$. The result confirms the general observation, that $\mathrm{Pd}(\mathrm{II})$ compounds are less toxic than $\mathrm{Pt}(\mathrm{II})$ compounds [7]. Therefore, palladium compounds are unlikely to be an alternative for cisplatin as cytostatic agents, unless they contain very active coordinated ligands. More studies may be needed, to account for the many factors affecting the cytostatic properties of metal complexes. For example, although for a long time, trans complexes of $\mathrm{Pt}(\mathrm{II})$ were believed to be inactive, many were later proven to be cytostatic $[36,37]$. There is also a possibility that a compound, while not being cytotoxic, may possess anticancer activity. For example, imidazolium trans-DMSO-imidazole-tetrachlororuthenate(III) (NAMI-A, for New Anti-tumor Metastasis Inhibitor) is not directly cytotoxic for most solid cancers, but acts as an anti-metastatic agent [38]. Moreover, while widely believed to be not toxic for tumors, NAMI-A was found to be highly cytotoxic for certain leukemia cell lines [39]. 
Table 4. Cytotoxic activity of 1,2 and cisplatin (CDDP) towards human cancer cell lines.

\begin{tabular}{|c|c|c|c|c|c|}
\hline Cell Line & $1 \mathrm{IC}_{50}(\mu \mathrm{M})$ & $115 \mu \mathrm{M}(\%)^{a}$ & $215 \mu \mathrm{M}(\%)^{\mathrm{a}}$ & CDDP $15 \mu \mathrm{M}(\%)^{a}$ & $\mathrm{CDDP} \mathrm{IC}_{50}(\mu \mathrm{M})$ \\
\hline A2780 & $57 \pm 3$ & ni & $54 \pm 9^{b}$ & $<10^{\mathrm{c}}$ & $0.6 \pm 0.03$ \\
\hline A2780cis & $50 \pm 6$ & ni & $65 \pm 3$ & $65 \pm 1$ & $20.2 \pm 0.7$ \\
\hline A549 & $79 \pm 13$ & ni & $71 \pm 13^{b}$ & $21 \pm 1.5$ & $3.9 \pm 0.5$ \\
\hline
\end{tabular}

${ }^{a}$ Percentage of live cells, relatively to the control of the solvent (DMSO) assumed as $100 \%$, in cultures treated with 1, 2 or CDDP at indicated concentrations for $72 \mathrm{~h}$; ${ }^{\mathrm{b}}$ results significantly different between the cell lines (Wilcoxon-Cox rank sum test, $p<0.05$ for two sided tests); ${ }^{\mathrm{C}}$ max. concentration tested was $10 \mu \mathrm{M}$; ni-no decrease in cell viability.

\section{Materials and Methods}

\subsection{Synthetic Procedures}

\subsubsection{Synthesis of Compound 1-(3-Hydroxyminoflavanone or 3-HIF)}

The synthesis was based on the procedure described by Kostka and Zyner [13], with small modifications. Briefly, $6 \mathrm{~g}$ of flavanone (Alfa Aesar, Karlsruhe, Germany) was dissolved in $450 \mathrm{~mL}$ of diethyl ether. Then, $9 \mathrm{~mL}$ of isopentyl nitrate(III) and $15 \mathrm{~mL}$ of 35\% hydrochloric acid were added. The mixture was gently shaken and left at $4-10{ }^{\circ} \mathrm{C}$ for $24 \mathrm{~h}$. The next day, the acidic layer was separated and discarded, and the ether solution was vigorously shaken with $150 \mathrm{~mL}$ of $1.5 \%-2 \%$ aqueous $\mathrm{NaOH}$ solution to extract the product as the sodium salt. The extraction was repeated twice. The alkalized water fraction was collected, cooled in an ice-water bath and acidified with pure acetic acid to $\mathrm{pH} \approx 3$. The resulting yellow precipitate of 1 was filtered off, washed with water and air dried. The crude product was recrystallized from hot toluene-methanol (10:1) solution and air dried again. M.w. = $253 \mathrm{~g} / \mathrm{mol}$; El. anal. Measured (calc.\%): C-71.24 (71.14), H—4.10 (4.38), N-4.42 (5.53); M.p. ${ }^{184-185}{ }^{\circ} \mathrm{C},{ }^{1} \mathrm{H}-\mathrm{NMR}\left(600 \mathrm{MHz}, \mathrm{DMSO}-d_{6}\right), \delta$ ppm 6.93 (s, 1H) 7.10-7.17 (m, 2 H) 7.24-7.28 $(\mathrm{m}, 2 \mathrm{H}) 7.30-7.38(\mathrm{~m}, 3 \mathrm{H}) 7.64(\mathrm{ddd}, J=8.56,7.06,1.69 \mathrm{~Hz}, 1 \mathrm{H}) 7.83(\mathrm{dd}, J=7.91,1.88 \mathrm{~Hz}, 1 \mathrm{H})$ 13.35-13.44 (m, 1H). A single crystal for X-ray analysis was obtained by slow evaporation of ethyl acetate from the solution of 1 at room temperature.

\subsubsection{Synthesis of Compound 2-[cis-(bis)(3-Nitrosoflavanone)-palladium(II)]}

The synthesis was based on the procedure described in [12] with modifications. Briefly, 2 mmol (506 mg) of yellow powder 1 was dissolved in $80 \mathrm{~mL} \mathrm{96 \%} \mathrm{ethanol} \mathrm{and} \mathrm{stirred.} \mathrm{Following} \mathrm{this,} 1 \mathrm{mmol}$ (326 mg) of potassium tetrachloropalladate(II) was dissolved in $10 \mathrm{~mL}$ of distilled water, added slowly to the ethanolic solution of $\mathbf{1}$ and left stirring at ambient temperature for $3-4 \mathrm{~h}$. Then, the orange precipitate was filtered off, and the solution was diluted with distilled water to precipitate more of the product. It was filtered off and the whole batch of the crude product was washed with water and air dried. The dry product was dissolved in chloroform, filtered and left for evaporation to obtain a red crystalline precipitate; then ground with diethyl ether and air dried again to remove any chloroform residues. M.w. $=611 \mathrm{~g} / \mathrm{mol}$; El. anal. Measured (calc.\%): C-58.41 (58.98), H-3.25 (3.30), N-4.54 (4.59); M.p. 211-213 ${ }^{\circ} \mathrm{C}, \mathrm{IR}\left(\mathrm{KBr}\right.$ disc) in $\mathrm{cm}^{-1}$ : 1608s, 1577s, 1528s, 1487s, $1467 \mathrm{~s}$, 1441s, 1413s, 1325m, 1280m, 1261m, 1213m, 1199 m, 1148 s, 1108 m, 1078 w, 1022 m, 960 w, 916 w, $862 \mathrm{~m}, 845 \mathrm{w}, 769 \mathrm{~m}, 751 \mathrm{~s}, 724 \mathrm{~m}, 796 \mathrm{~m}, 667 \mathrm{~m}, 627 \mathrm{w}, 595 \mathrm{w}, 557 \mathrm{w}, 518 \mathrm{w}, 468 \mathrm{w}$. (s-strong, less than 25\% transmittance; m-medium, 25\%-55\% transmittance; w-weak, 55\%-70\% transmittance). ${ }^{1} \mathrm{H}-\mathrm{NMR}$ $\left(600 \mathrm{MHz}, \mathrm{CDCl}_{3}\right), \delta$ ppm: $6.56(\mathrm{~d}, J=1.13 \mathrm{~Hz}, 2 \mathrm{H}) 7.01(\mathrm{dd}, J=8.47,5.46 \mathrm{~Hz}, 2 \mathrm{H}) 7.10-7.16(\mathrm{~m}, 2 \mathrm{H})$ 7.25-7.35 (m, 13H) 7.54-7.62 (m, 2H) $8.10(\mathrm{dt}, J=7.91,1.69 \mathrm{~Hz}, 2 \mathrm{H})$. A single crystal for X-ray analysis was obtained by slow evaporation of chloroform from the solution of 2 at room temperature. 


\subsection{Crystallography and Theoretical Calculations}

\subsubsection{X-ray Measurements and Spherical Structure-Refinements (IAM-Independent-Atom Models)}

The crystal and molecular structures of 1-2 were determined by single-crystal X-ray diffraction. Data collection was carried out at $100 \mathrm{~K}$ with an Agilent SuperNova diffractometer with an Atlas detector (Agilent Technologies, Yarnton, Oxfordshire, UK) (1) and an Oxford Xcalibur diffractometer with a Sapphire3 detector (Oxford Diffraction, Abingdon, UK) (2), both using MoK $\alpha$ radiation and $\omega$ scan. The data reduction and multi-scan absorption correction were performed by CrysAlis PRO [40] and CrysAlis RED [41] software for $\mathbf{1}$ and 2, respectively. Both structures were solved by direct methods and refined by full-matrix least-square procedures on $F^{2}$ using the SHELXL-2013 [42] program package implemented in WinGX [43]. All non-hydrogen atoms were refined anisotropically. The (O)-H-atom (H3A) involved in the $\mathrm{O}-\mathrm{H} \cdots \mathrm{O} / \mathrm{N}$ hydrogen bonds in structure $\mathbf{1}$ was located in a Fourier map and refined freely. The remaining $(\mathrm{C})-\mathrm{H}$ atoms were calculated to their idealized positions and refined as riding atoms with isotropic displacement parameters $U_{\text {iso }}(\mathrm{H})=1.2 U_{\text {eq }}(\mathrm{C})$. Three chlorine atoms $(\mathrm{Cl1}$, $\mathrm{Cl} 2, \mathrm{Cl3}$ ) and one carbon atom (C31) in the solvent molecule (trichloromethane) of structure 2 were found to be disordered and refined in two alternative positions with the final site-occupation factors: $k_{\mathrm{A}}: k_{\mathrm{B}}=0.5889(16): 0.4111(16)$. The solvent-hydrogen atom (H31) was refined freely. The crystallographic data and the final figures of merit for spherical refinements of 1-2 are presented in Table 1.

\subsubsection{X-ray Wavefunction Refinement (XWR)}

The geometry of ligand molecule 1 obtained from spherical refinement (IAM model, all $\mathrm{H}$-atoms refined freely) was used as input for the Hirshfeld-atom refinement $[15,16]$ (HAR). In HAR, the following structural parameters were refined freely: coordinates for all atoms, anisotropic displacements parameters (ADPs) for non-hydrogen atoms and isotropic displacement parameters $\left(U_{\text {iso }}\right)$ for H-atoms. The final geometry of $\mathbf{1}$, obtained by Hirshfeld-atom refinement was used as input for X-ray constrained wavefunction fitting (XCW). In the fitting procedure, the obtained wavefunction was constrained to the experimental data by introducing the Lagrange parameter; final $\lambda=0.10$. Both steps of X-ray wavefunction refinement [22] (XWR $=\mathrm{HAR}+\mathrm{XCW}$ ) were performed using blyp/cc-pVTZ [44-46] level of theory within the Tonto [47] software package. In order to simulate the effect of the crystal environment, a cluster of charges and dipoles around the central molecule was introduced: all molecules with at least one atom within a radius of $8 \AA$ around the central molecule were included in the surrounding cluster. All calculations were carried out on $F$. Negative intensities $|F|^{2}$ as well as reflections with $|F|<2.0 \sigma(|F|)$ were pruned from the data. Hence the number of data used in spherical refinement and XWR differs. The final figures of merit are summarized in Table 1. The residual density map (Figure S1a) is essentially featureless, and the deformation density plot (Figure S1b) shows only the expected characteristics.

\subsubsection{Theoretical Calculations}

Starting from the experimental coordinates (taken from IAM models) gas-phase structures of $\mathbf{1}$ and 2 were obtained by full geometry optimizations at the same level of theory, blyp/cc-pVTZ, as X-ray wavefunction refinement. In the case of $\mathbf{2}$, the effective core potential for the Pd atom (ECP28MDF) [48] was used along with the associated triple- $\zeta$ basis set, the cc-pVTZ basis set was also used for all other atoms. The final geometries were confirmed to be minima by an analysis of harmonic vibrational frequencies. All computations were performed using the Gaussian09 [49] program.

\subsubsection{QTAIM (Quantum Theory of Atoms in Molecules) and ELI-D (Electron Localizability Indicator) Analyses}

QTAIM [21] and ELI-D [23,24] analyses. The wavefunction derived by the XCW procedure and those obtained from DFT-optimizations were analyzed using AIMALL [50] to calculate all the bond and atomic properties presented in this study. Moreover, the X-ray constrained wavefunction of $\mathbf{1}$ and 
theoretically obtained checkpoint files of $\mathbf{1}$ and $\mathbf{2}$ (OPT models) were used in ELI-D analysis. For the grid calculations with DGRID-4.6 [51], a step size of $0.05 \mathrm{bohr}$ was applied. The AIM graphs were displayed with AIMAll (Figure 1c,d). ELI-D graphs were created with MOLISO [52] (Figure 1e,f).

\subsection{NMR Spectroscopic Analysis}

NMR spectra were collected at the Laboratory of Molecular Spectroscopy, Faculty of Chemistry, University of Lodz, Poland, on a Bruker Avance III $600 \mathrm{MHz}$ spectrophotometer (Bruker Corporation, Billerica, MA, USA), at room temperature, in DMSO- $d_{6}$ or $\mathrm{CDCl}_{3}$. The ${ }^{13} \mathrm{C}-\mathrm{NMR}$ spectrum of 1 in DMSO- $d_{6}$ was recorded on apparatus Bruker (Bruker Corporation) $300 \mathrm{MHz}$ at the Medical University of Lodz.

\subsection{Solution Stability Studies: UV-Vis Spectroscopy}

UV-Vis spectra were collected using Spectrostar Nano spectrophotometer (BMG LABTECH $\mathrm{GmbH}$, Ortenberg, Germany). The complex 2 was dissolved in DMSO at the concentration $7 \mathrm{mM}$, and then diluted in water at $15 \mu \mathrm{M}$, to achieve DMSO concentration $0.2 \% v / v$. The solution was incubated at $37^{\circ} \mathrm{C}$ in a covered quartz cuvette, and the spectra were collected during $62 \mathrm{~h}$ of incubation.

\subsection{Cell Culture and Cytotoxicity Assay}

\subsubsection{Cell Culture}

The cell lines A2780 (human ovarian carcinoma, ECACC cat. No. 93112519), A2780cis (subline resistant to cisplatin, ECACC cat. No. 93112517) and A549 (human non-small cell lung carcinoma, ECACC cat. No. 86012804) were purchased from Sigma-Aldrich. The cells were cultured in RPMI-1640 medium (Biological Industries, Kibbutz Beit Haemek, Israel) supplemented with 10\% heat inactivated fetal bovine serum, $5 \mathrm{mM}$ Hepes and $50 \mu \mathrm{g} / \mathrm{mL}$ gentamycin. A549 cells were cultured in high-glucose DMEM medium (Biological Industries) supplemented with 10\% heat inactivated fontal bovine serum, $5 \mathrm{mM}$ Hepes and $50 \mu \mathrm{g} / \mathrm{mL}$ gentamycin. All cell lines were maintained in a humidified incubator at $37^{\circ} \mathrm{C}, 5 \% \mathrm{CO}_{2}$. The cell lines were grown as monolayers, and renewed every $3-4$ days.

\subsubsection{Cytotoxicity Assay (3-(4,5-Dimethylthiazol-2-yl)-2,5-diphenyltetrazolium Bromide or} MTT Assay)

The cells were seeded in 24-well plates (TPP), $1 \mathrm{~mL}$ of cell suspension per well, at the following densities: A2780-10 $0^{4}$ cells $/ \mathrm{mL}$, and A2780cis and A549-1.5. $10^{4}$ cells $/ \mathrm{mL}$. The next day, the tested compounds (1, 2 and CDDP) were added, pre-dissolved in DMSO (at the max. concentration $7.5 \mathrm{mM}$ ) and then dissolved in the complete culture medium, at concentrations twice those of the final ones, and $1 \mathrm{~mL}$ of resulting solution was added per well. The solutions of 2 and CDDP compounds were freshly made before every experiment to avoid the solvolysis $[53,54]$. Stock solution of 1 was stored refrigerated. Final concentration of DMSO in culture medium was $0.2 \% v / v$. After $72 \mathrm{~h}$, MTT solution in PBS was added to a final concentration of $0.25 \mathrm{mg} / \mathrm{mL}$ in culture. The suspension was then incubated at $37^{\circ} \mathrm{C}$ until visible color appeared (approximately $1 \mathrm{~h}$ ). The culture medium was then removed, and the purple formazan crystals dissolved in $1 \mathrm{~mL}$ of DMSO. The absorbance was read at $\lambda=540 \mathrm{~nm}$ on a Spectrostar Nano microplate reader. Every concentration was measured in triplicate, and each experiment was repeated on at least three separate plates. The results are displayed as percentages of the solvent control (assumed to be 100\%), and shown as the mean value \pm standard deviation (see Figure S6 in Supplementary Materials).

\section{Conclusions}

The work presents a detailed description of the structure of 3-hydroxyiminoflavanone and its palladium(II) complex, and sheds new light on their structures in solution and in solid state. It shows that $3 E$ (anti)-hydroxyiminoflavanone (1) reacts with tertrachloridopalladate(II) and forms complex 
2, while the ligands lose their oxime proton. The polar environment of the reaction may affect the structure of the ligand, and therefore the complex, by promoting the existence of the $E$ (anti) form of $\mathbf{1}$. Non-polar solvents, such as chloroform, probably support the formation of $Z$ (syn) isomer of $\mathbf{1}$. A combination of $X$-ray single-crystal structure determination and electron-density studies of $\mathbf{2}$ show that cis-(bis)(3-nitrosoflavanone)-palladium(II) is formed, and the donor atoms of the ligand are the carbonyl oxygen and oxime nitrogen. 3-hydroxyiminoflavanone thus becomes 3-nitrosoflavanone when coordinated to the $\mathrm{Pd}(\mathrm{II})$ ion. An analysis of the real-space bonding indicators considered in this study, i.e., all geometrical, topological and integrated parameters describing properties of chemical bonds, reveals $\pi$-delocalization within the flavanone moieties of structure 2 . Probably due to the lack of any polar moieties on the outer surface of the molecule, the emerging complex is hardly soluble in polar solvents. At a concentration of $15 \mu \mathrm{M}$ in the culture media, compounds 1 and 2 are only moderately cytotoxic towards three human cancer cell lines, and the little difference observed in cytotoxicity towards cisplatin-sensitive and cisplatin-resistant sublines of A2780 suggests that they do not distinguish between the two cell lines.

Supplementary Materials: Supplementary materials can be accessed at: http://www.mdpi.com/1420-3049/ $21 / 4 / 455 /$ s1.

Acknowledgments: Authors acknowledge the financial support from the Polish National Science Centre (grant No. 6740/B/P01/2011/40; reg. No. N N405 674040) and the statute fund from Medical University of Lodz (503/3-016-02/503-31-001, and 502-03/3-016-02/502-34-062). The open access publishing fee was covered by the Faculty of Pharmacy Dean's (Medical University of Lodz) fund No 503/3-016-02/503-36-001. We thank Agnieszka Zdolska for her help in the preparation of the compounds. Collecting the X-ray data was ordered to be done in Department of Physics of the Crystals, at the University of Silesia in Katowice, Poland. Collecting NMR spectra were recorded to in Laboratory of Molecular Spectroscopy, Faculty of Chemistry, University of Lodz, Poland.

Author Contributions: J.O. conceived preliminary research and initiated the theme; M.K. and M.F. conceived and designed the experiments and performed the experiments; M.K. and L.C. analyzed the data; M.K., M.F. and L.C. wrote the paper; and L.S. contributed laboratory access and the manuscript correction.

Conflicts of Interest: The authors declare no conflict of interest.

\section{Abbreviations}

The following abbreviations are used in this manuscript:

1

2

CDDP

$\mathrm{DMF}$

DMSO

ELI-D

3-hydroxyiminoflavanone

HAR

cis-(bis)(3-nitrosoflavanone)palladium(II)

IAM

cis-diaminnadichloridoplatinum(II) or cisplatin

MTT

$N^{\prime}-N^{\prime}$-dimethylformamide

dimethylsulfoxide

Electron Localizability Indicator

NAMI-A

Hirshfeld Atom Refinement

Independent Atom Model

NAMI-A
NMR

3-(4,5-dimethylthiazol-2-yl)-2,5-diphenyltetrazolium bromide

QTAIM

New Anti-tumor Metastasis Inhibitor or imidazolium

trans-DMSO-imidazole-tetrachlororuthenate(III)

XWR

Nuclear Magnetic Resonance

Quantum Theory of Atoms in Molecules

X-ray wavefunction refinement

\section{References}

1. Heffeter, P.; Jungwirth, U.; Jakupec, M.; Hartinger, C.; Galanski, M.; Elbling, L.; Micksche, M.; Keppler, B.; Berger, W. Resistance against novel anticancer metal compounds: Differences and similarities. Drug Resist. Updates 2008, 11. [CrossRef] [PubMed]

2. Kostova, I. Platinum complexes as anticancer agents. Recent Pat. Anti-Cancer Drug Discov. 2006, 1. [CrossRef] 
3. Zhang, C.X.; Lippard, S.J. New metal complexes as potential therapeutics. Curr. Opin. Chem. Biol. 2003, 7, 481-489. [CrossRef]

4. Garoufis, A.; Hadjikakou, S.K.; Hadjiliadis, N. Palladium coordination compounds as anti-viral, anti-fungal, anti-microbial and anti-tumor agents. Coord. Chem. Rev. 2009, 253, 1384-1397. [CrossRef]

5. Iakovidou, Z.; Papageorgiou, A.; Demertzis, M.A.; Mioglou, E.; Mourelatos, D.; Kotsis, A.; Yadav, P.N.; Kovala-Demertzi, D. Platinum(II) and palladium(II) complexes with 2-acetylpyridine thiosemicarbazone: Cytogenetic and antineoplastic effects. Anti-Cancer Drugs 2001, 12, 65-70. [CrossRef]

6. Zhao, G.H.; Lin, H.K.; Yu, P.; Sun, H.W.; Zhu, S.R.; Su, X.C.; Chen, Y.T. Ethylenediamine-palladium(II) complexes with pyridine and its derivatives: Synthesis, molecular structure and initial antitumor studies. J. Inorg. Biochem. 1999, 73, 145-149. [CrossRef]

7. Jamieson, E.R.; Lippard, S.J. Structure, recognition, and processing of cisplatin-DNA adducts. Chem. Rev. 1999, 99, 2467-2498. [CrossRef] [PubMed]

8. Budzisz, E.; Keppler, B.K.; Giester, G.; Wozniczka, M.; Kufelnicki, A.; Nawrot, B. Synthesis, crystal structure and biological characterization of a novel palladium(II) complex with a coumarin-derived ligand. Eur. J. Inorg. Chem. 2004, 2004, 4412-4419. [CrossRef]

9. Kasprzak, M.M.; Erxleben, A.; Ochocki, J. Properties and applications of flavonoid metal complexes. RSC Adv. 2015, 5, 45853-45877. [CrossRef]

10. Kosmider, B.; Osiecka, R.; Ciesielska, E.; Szmigiero, L.; Zyner, E.; Ochocki, J. Induction of apoptosis and necrosis in lymphocytes by the cis-Pt(II) complex of 3-aminoflavone in comparison with cis-DDP. Mutat. Res. Genet. Toxicol. Environ. Mutagen. 2004, 558, 169-179. [CrossRef] [PubMed]

11. Jakupec, M.A.; Galanski, M.; Keppler, B.K. Tumour-inhibiting platinum complexes-State of the art and future perspectives. Rev. Physiol. Biochem. Pharmacol. 2003, 146, 1-53.

12. Zyner, E.; Ochocki, J. Platinum(II) and palladium(II) N,O-chelates with substituted flavanone containing ligands. Acta Pol. Pharm. Drug Res. 1999, 56, 159-167.

13. Kostka, K.; Zyner, E. Structure and protolytic equilibria of 3-hydroxyiminoflavanone. Chem. Anal. 1987, 32, 253-261.

14. Macrae, C.F.; Bruno, I.J.; Chisholm, J.A.; Edgington, P.R.; McCabe, P.; Pidcock, E.; Rodriguez-Monge, L.; Taylor, R.; van de Streek, J.; Wood, P.A. Mercury CSD 2.0-New features for the visualization and investigation of crystal structures. J. Appl. Crystallogr. 2008, 41, 466-470. [CrossRef]

15. Jayatilaka, D.; Dittrich, B. X-ray structure refinement using aspherical atomic density functions obtained from quantum-mechanical calculations. Acta Crystallogr. Sect. A 2008, 64, 383-393. [CrossRef] [PubMed]

16. Capelli, S.C.; Bürgi, H.-B.; Dittrich, B.; Grabowsky, S.; Jayatilaka, D. Hirshfeld atom refinement. IUCrJ 2014, 1,361-379. [CrossRef] [PubMed]

17. Ha, K. A second monoclinic polymorph of (pyridine-2-carboxaldehyde oximato- $\kappa^{2} N, N^{\prime}$ ) (pyridine-2carboxaldehyde oxime- $\kappa^{2} N, N^{\prime}$ )palladium(II) chloride. Acta Crystallogr. Sect. E 2012, 68, m176-m177. [CrossRef] [PubMed]

18. Torabi, A.A.; Soudozi, A.; Welter, R. Crystal structure of (pyridine-2-aldoxime- $N, N^{\prime}$ )palladium(II) chloride, $\left[\mathrm{Pd}\left(\mathrm{C}_{12} \mathrm{H}_{11} \mathrm{ClN}_{4} \mathrm{O}_{2}\right)\right] \mathrm{Cl}$. Z. Kristallogr. NCS 2007, 222, 197-198. [CrossRef]

19. Cremer, D.; Pople, J.A. General definition of ring puckering coordinates. J. Am. Chem. Soc. 1975, 97, 1354-1358. [CrossRef]

20. Duax, L.; Norton, D.A. Atlas of Steroid Structure; IFI/Plenum: New York, NY, USA, 1975; Volume 1, pp. 16-22.

21. Bader, R.F.W. Atoms in molecules. In A Quantum Theory; Oxford University Press: Oxford, UK, 1990.

22. Grabowsky, S.; Luger, P.; Buschmann, J.; Schneider, T.; Schirmeister, T.; Sobolev, A.N.; Jayatilaka, D. The significance of ionic bonding in sulfur dioxide: Bond orders from X-ray diffraction data. Angew. Chem. Int. Ed. 2012, 51, 6776-6779. [CrossRef] [PubMed]

23. Kohout, M. A measure of electron localizability. Int. J. Quantum Chem. 2004, 97, 651-658. [CrossRef]

24. Kohout, M.; Wagner, F.R.; Grin, Y. Electron localizability indicator for correlated wavefunctions. III: Singlet and triplet pairs. Theor. Chem. Acc. 2008, 119, 413-420. [CrossRef]

25. Bader, R.F.W.; Slee, T.S.; Cremer, D.; Kraka, E. Description of conjugation and hyperconjugation in terms of electron distributions. J. Am. Chem. Soc. 1983, 105, 5061-5068. [CrossRef]

26. Bader, R.F.W.; Stephens, M.E. Spatial localization of the electronic pair and number distributions in molecules. J. Am. Chem. Soc. 1975, 97, 7391-7399. [CrossRef] 
27. Fradera, X.; Austen, M.A.; Bader, R.F.W. The Lewis model and beyond. J. Phys. Chem. A 1999, 103, $304-314$. [CrossRef]

28. Espinosa, E.; Alkorta, I.; Elguero, J.; Molins, E. From weak to strong interactions: A comprehensive analysis of the topological and energetic properties of the electron density distribution involving $\mathrm{X}-\mathrm{H} \cdots \mathrm{F}-\mathrm{Y}$ systems. J. Chem. Phys. 2002, 117, 5529-5542. [CrossRef]

29. Raub, S.; Jansen, G. A quantitative measure of bond polarity from the electron localization function and the theory of atoms in molecules. Theor. Chem. Acc. 2001, 106, 223-232. [CrossRef]

30. Vidal, I.; Melchor, S.; Dobado, J.A. On the nature of metal-carbon bonding: AIM and ELF analyses of MCHn ( $n=1-3)$ compounds containing early transition metals. J. Phys. Chem. A 2005, 109, 7500-7508. [CrossRef] [PubMed]

31. Gonewar, N.R.; Jadhav, V.B.; Jadhav, K.D.; Sarawadekar, R.G. Theoretical calculations of infrared, NMR and electronic spectra of 2-nitroso-1, naphthol or 1-2 naphthoquinine-2 oxime and comparison with experimental data. Res. Pharm. 2012, 2, 18-25.

32. Belmar, J.; Quezada, J.; Jimenez, C.A.; Diaz-Gallifa, P.; Pasan, J.; Ruiz-Perez, C. Synthesis, crystal structures and tautomerism in novel oximes based on hydroxyalkylpyrazolones. New J. Chem. 2013, 37, 2002-2010. [CrossRef]

33. Enchev, V.; Angelova, S. Does tautomeric equilibrium exist in 4-nitroso-5-pyrazolones? J. Mol. Struct. Theochem. 2009, 897, 55-60. [CrossRef]

34. Enchev, V.; Ivanova, G.; Stoyanov, N. Tautomeric and conformational equilibrium of 2-nitrosophenol and 9,10-phenanthrenequinonemonooxime: Ab initio and NMR study. J. Mol. Struct. Theochem. 2003, 640, 149-162. [CrossRef]

35. Enchev, V.; Ivanova, G.; Ugrinov, A.; Neykov, G.D. Tautomeric and conformational equilibrium of acenaphthenequinonemonooxime. J. Mol. Struct. 1999, 508, 149-161. [CrossRef]

36. Fabijanska, M.; Studzian, K.; Szmigiero, L.; Rybarczyk-Pirek, A.J.; Pfitzner, A.; Cebula-Obrzut, B.; Smolewski, P.; Zyner, E.; Ochocki, J. Trans-platinum(II) complex of 3-aminoflavone-Synthesis, X-ray crystal structure and biological activities in vitro. Dalton Trans. 2015, 44, 938-947. [CrossRef] [PubMed]

37. Kalinowska-Lis, U.; Ochocki, J.; Matlawska-Wasowska, K. Trans geometry in platinum antitumor complexes. Coord. Chem. Rev. 2008, 252, 1328-1345. [CrossRef]

38. Rademaker-Lakhai, J.M.; van den Bongard, D.; Pluim, D.; Beijnen, J.H.; Schellens, J.H. A Phase I and pharmacological study with imidazolium-trans-DMSO-imidazole-tetrachlororuthenate, a novel ruthenium anticancer agent. Clin. Cancer Res. 2004, 10, 3717-3727. [CrossRef] [PubMed]

39. Pillozzi, S.; Gasparoli, L.; Stefanini, M.; Ristori, M.; D'Amico, M.; Alessio, E.; Scaletti, F.; Becchetti, A.; Arcangeli, A.; Messori, L. NAMI-A is highly cytotoxic toward leukaemia cell lines: Evidence of inhibition of KCa 3.1 channels. Dalton Trans. 2014, 43, 12150-12155. [CrossRef] [PubMed]

40. CrysAlis PRO; Ver. 1.171.36.32; Agilent Technologies: Yarnton, UK, 2013.

41. CrysAlis RED; Ver. 1.171.32.29; Oxford Diffraction: Abingdon, UK, 2008.

42. Sheldrick, G.M. A short history of shelx. Acta Crystallogr. Sect. A 2008, 64, 112-122. [CrossRef] [PubMed]

43. Farrugia, L.J. WinGX and ORTEP for Windows: An update. J. Appl. Crystallogr. 2012, 45, 849-854. [CrossRef]

44. Becke, A.D. Density-functional exchange-energy approximation with correct asymptotic-behavior. Phys. Rev. A 1988, 38, 3098-3100. [CrossRef]

45. Dunning, T.H. Gaussian-basis sets for use in correlated molecular calculations. I. The atoms boron through neon and hydrogen. J. Chem. Phys. 1989, 90, 1007-1023. [CrossRef]

46. Lee, C.T.; Yang, W.T.; Parr, R.G. Development of the Colle-Salvetti correlation-energy formula into a functional of the electron-density. Phys. Rev. B 1988, 37, 785-789. [CrossRef]

47. Jayatilaka, D.; Grimwood, D.J. Tonto: A fortran based object-oriented system for quantum chemistry and crystallography. In Computational Science_ICCS 2003; Part 4; Springer: New York, 2003; Volume 2660, pp. 142-151.

48. Peterson, K.A.; Figgen, D.; Dolg, M.; Stoll, H. Energy-consistent relativistic pseudopotentials and correlation consistent basis sets for the $4 \mathrm{~d}$ elements Y-Pd. J. Chem. Phys. 2007, 126. [CrossRef] [PubMed]

49. Frisch, M.J.; Trucks, G.W.; Schlegel, H.B.; Scuseria, G.E.; Robb, M.A.; Cheeseman, J.R.; Scalmani, G.; Barone, V.; Mennucci, B.; Petersson, G.A.; et al. Gaussian 09; Rev. D.01; Gaussian, Inc.: Wallingford, CT, USA, 2013.

50. Keith, T.A. AIMAll (Ver. 14.11.23); TK Gristmill Software: Overland Park, KS, USA, 2014. 
51. Kohout, M. Dgrid-4.6. Available online: http://www.cpfs.mpg.de/ kohout/dgrid.html (accessed on 15 May 2015).

52. Hübschle, C.B.; Luger, P. Moliso-A program for colour-mapped iso-surfaces. J. Appl. Crystallogr. 2006, 39, 901-904. [CrossRef]

53. Fischer, S.J.; Benson, L.M.; Fauq, A.; Naylor, S.; Windebank, A.J. Cisplatin and dimethyl sulfoxide react to form an adducted compound with reduced cytotoxicity and neurotoxicity. Neurotoxicology 2008, 29, 444-452. [CrossRef] [PubMed]

54. Sundquist, W.I.; Ahmed, K.J.; Hollis, L.S.; Lippard, S.J. Solvolysis reactions of cis- and trans-diamminedichloroplatinum(ii) in dimethyl sulfoxide. Structural characterization and DNA binding of trans-bis(ammine)chloro(DMSO)platinum(1+). Inorg. Chem. 1987, 26, 1524-1528. [CrossRef]

Sample Availability: Samples of the compounds 1 and 2 are available from the authors.

(C) 2016 by the authors; licensee MDPI, Basel, Switzerland. This article is an open access article distributed under the terms and conditions of the Creative Commons Attribution (CC-BY) license (http://creativecommons.org/licenses/by/4.0/). 